\title{
Trends in Household Air Pollution Contributed by the Type of Cooking Fuel Used in Ugandan Households from 2000 to 2016 and Associated Household Factors: An Analysis of Demographic and Health Surveys
}

Derrick Bary Abila ( $\sim$ abilabary@yahoo.com )

Makerere University College of Health Sciences

Nalunkuma Racheal

Makerere University College of Health Sciences

Sulaiman Bugosera Wasukira

Infectious Diseases Institute

\section{Provia Ainembabazi}

Infectious Diseases Institute

\section{Aggrey Siya}

Makerere University

Ruth Ketty Kisuza

Makerere University College of Health Sciences

Elizabeth Kiyingi Nakiyingi

Makerere University College of Health Sciences

Asia Mustafa

Makerere University College of Health Sciences

\section{Yusuff Adebayo Adebisi}

Faculty of Pharmacy, University of Ibadan

Don Eliseo Lucero-Prisno III

Department of Global Health and Development, London School of Hygiene and Tropical Medicine

\section{Research Article}

Keywords: Household air pollution, Public Health, DHS, Uganda

Posted Date: September 14th, 2021

DOl: https://doi.org/10.21203/rs.3.rs-783438/v1 
License: (c) (i) This work is licensed under a Creative Commons Attribution 4.0 International License. Read Full License 


\section{Abstract \\ Background}

The type of cooking fuel used in households can expose the members to polluted air which has been shown to have multiple health effects. We describe the trend in household air pollution (HAP) caused by the type of cooking fuel used in Ugandan households from 2001 to 2016 and explore the household factors associated with it.

\section{Methods}

This was a retrospective analysis of four datasets of Ugandan demographic and health surveys (DHS) conducted from 2000/2001 to 2016 with the household as the unit of analysis. We included variables that described the households, the type of cooking fuel, and where the food was cooked. A household was considered to have exposure to HAP if they used cooking fuels like coal, charcoal, wood, straw/shrubs/grass, crops, or animal dung for cooking. Bivariate and multivariate logistic regression was used to determine the association between household characteristics and exposure to household air pollution (HAP) from the most recent DHS of 2016.

\section{Results}

A total of 45,376 households were included in the study. In all the surveys, the majority of the households were rural $(74.33-85.11 \%)$, were headed by a male (68.98-72.46\%), and with their highest educational attainment as incomplete primary education (37.21-42.44\%). In all the surveys, the majority of the households used wood as a cooking fuel (71.69-82.08\%). Most of the households were exposed to HAP (96.69-99.80\%). From the multivariate logistic regression analysis, households with a household head having attained either complete secondary education [Adjusted Odd ratio: 0.13, 95\% Confidence interval (0.03-0.58), $\mathrm{p}$-value $=0.008$ ] or higher education [Adjusted Odd ratio: $0.11,95 \%$ Confidence interval $(0.03-0.48), p$-value $=0.003$ ] were less likely to be exposed to HAP when compared with households with a household head having no education.

\section{Conclusions}

This study revealed that most households in Uganda have exposure to household air pollution caused by the type of cooking fuel used in the household. This underscores the need for innovations in cooking fuels like clean energy stoves that are cost-effective and cause less exposure to household air pollution.

\section{Background}


One of the biggest contributors to air pollution is household air pollution (HAP). HAP refers to the exposure of members of a household to particulate matter with an aerodynamic diameter less than or equal to $2.5 \mu \mathrm{m}\left(\mathrm{PM}_{2.5}\right)$ mostly due to solid cooking fuels, such as coal, wood, and agricultural residues [1]. According to the 2017 Global Burden of Disease report, exposure to HAP was the second-highest environmental risk factor [2].

Household air pollution is one of the leading causes of diseases and premature deaths in the developing world [3]. Household air pollution has been shown to affect the health of the populations and is associated with disease conditions like cardiovascular diseases, chronic lung diseases, pneumonia in children, and anemia $[3,4]$. This increases the morbidity and mortality rates associated with HAP. In 2019, the Disability Adjusted Life Years (DALYs) associated with HAP was 91.5 million DALYs [5]. The major source of HAP is the type of cooking fuel that is used in the household. These cooking fuels include coal, wood, grass/shrubs, animal dung, and crops [3]. To reduce exposure to HAP caused by the type of cooking fuel used in a household, we need to determine the prevalence and describe the factors associated with HAP. There exist large population-based survey datasets that include variables that can be used to monitor the exposure to HAP in countries [6]. For example, the Demographic and Health Surveys (DHS) conducted periodically in the majority of the low- and middle-income countries (LMICs) collect information on the type of cooking fuel used by households.

In this study, we aimed at determining the exposure of households to household air pollution (HAP) caused by the type of cooking fuel used in Ugandan households from 2001 to 2016 and explore the household factors associated with it.

\section{Methods}

\section{Study design and setting}

This was a retrospective analysis of open access data collected by the Demographic and Health Surveys (DHS) in Uganda. The surveys included in this study were conducted in Uganda at four time points i.e., 2000/2001, 2006, 2011, and 2016. "The Demographic and Health Surveys (DHS) are internationally comparable household surveys that collect information on demographic, socioeconomic, and healthrelated variables among nationally representative samples of households in developing countries. Details of the DHS sampling design and strategies are described elsewhere" [7].

\section{Study population}

Data analyzed in this study included information on households found in the final datasets shared on the DHS program website. The unit of analysis was households. During the survey interviews, either the household head or any other consenting adults with knowledge about the household responded to questions about the household.

\section{Study variables}


The variables that described the household included in the study were (1) number of household members, (2) type of place of residence (urban or rural), (3) sex of household head, (4) age of household head, (5) wealth index of the household and (6) educational attainment of the household head.

The variable attributed to household air pollution was the type of cooking fuel used in the household. A household was considered to have exposure to HAP if they used cooking fuels like coal, charcoal, wood, straw/shrubs/grass, crops/crop residues, or animal dung/matter for cooking. Non-exposure of a household to HAP was considered if they used cooking fuels like electricity, liquefied petroleum gas (LPG), or natural gas/biogas. Also, variables on where food was cooked (food cooked in the house, separate building, or outdoors) and whether the household had a separate room used as a kitchen (for those who cook in the house).

\section{Data management}

The final DHS datasets were downloaded after obtaining permission from the DHS program website. A new binary variable for measuring exposure or non-exposure to HAP was generated from the variable about the type of cooking fuel used after excluding households in which food was not cooked (coded 95) and those that did not specify the type of cooking fuel used (coded 96).

\section{Data analysis}

All the analysis in this study was performed in STATA 13 and each survey dataset was analyzed separately [8]. Weighting was performed for all the descriptive statistics using the weight variable (v005) after dividing it by $1,000,000$, as recommended by the DHS statistics guide [9].

$$
\text { weight(wgt) }=\frac{\mathrm{v} 005(\text { weightvariable })}{1,000,000}
$$

For the regression analysis in STATA 13, weighting was also performed using the Primary Sampling Unit (PSU) and Strata as the variables v021 and v022 respectively in the DHS survey datasets for the surveys and weight (wgt) calculated previously. The STATA13 code below was used to apply weights before calculating means, standard deviation, and $95 \%$ confidence intervals of continuous variables and regression analysis.

svyset v021 [pw $=$ wgt], strata(v022) singleunit(centered)

where pw is the probability weight (sampling weight), psu is the primary sampling unit, v021 is the variable for the primary sampling unit, and 022 is the variable in the DHS that indicates the strata used in the DHS surveys.

\section{Summary statistics}

Categorical variables were summarized as weighted proportions. For the numerical variables such as age, they were summarized as weighted means with $95 \%$ confidence intervals [8]. 
We used bivariate and multivariate logistic regression to determine the association between household characteristics and exposure to household air pollution (HAP) for each of the individual surveys. We reported crude odds ratios, adjusted odds ratios, p-values, and $95 \%$ confidence intervals. First, bivariate logistic regression was used to determine the association between HAP and individual household characteristics. Then, multivariate logistic regression was used including the statistically significant variables (1) type of place of residence (urban vs rural), (2) age of household head, (3) wealth index of the household, and (4) household heads education attainment.

\section{Quality control}

To ensure that we are working with the correct DHS dataset for a given year, a test analysis was performed to try to replicate the tables in the respective DHS survey reports for the various years. We created a frequency distribution table for the variable of the type of place of residence for the different years in STATA13 and compared the result with what was reported in the respective DHS survey report. All results from this test analysis matched those in the DHS survey reports.

\section{Results}

\section{Household characteristics}

A total of 45,376 households were included in the study from the four DHS surveys conducted from $2000 / 2001$ to 2016 . The lowest mean number of household members was 4.6 people in 2016 . In all the surveys, the majority of the households were in rural areas ranging from $74.33 \%$ in 2016 to $85.11 \%$ in $2000 / 2001$. For all the surveys, the majority of the households were headed by a male with an average age ranging from 41.54 years in 2000/2001 to 42.23 years in 2016. The majority of the households were in the highest wealth index category. In all the surveys, most of the household heads had their highest educational attainment as incomplete primary education ranging from $37.21 \%$ in 2016 to $42.44 \%$ in 2000/2001 (Table 1). Household fuel use and household air pollution (HAP) 
Table 1

Demographic characteristics of the households that participated in the DHS surveys of 2000/2001 to 2016.

\begin{tabular}{|c|c|c|c|c|}
\hline Household characteristics & $2000 / 2001$ & 2006 & 2011 & 2016 \\
\hline Number of Households & 7885 & 8870 & 9033 & 19,588 \\
\hline \multicolumn{5}{|c|}{ Number of household members } \\
\hline Mean (SD) & $4.96(2.90)$ & $5.13(2.88)$ & $4.99(2.81)$ & $4.6(2.7)$ \\
\hline 95\% Confidence Interval & $4.85-5.06$ & $5.03-524$ & $4.88-5.09$ & $4.6-4.7$ \\
\hline \multicolumn{5}{|l|}{ Type of place } \\
\hline Urban & $1174(14.89 \%)$ & $1389(15.66 \%)$ & $1691(18.72 \%)$ & $5027(25.67 \%)$ \\
\hline Rural & $6711(85.11 \%)$ & $7481(84.34 \%)$ & $7342(81.28 \%)$ & $14561(74.33 \%)$ \\
\hline \multicolumn{5}{|l|}{ Sex of household head } \\
\hline Male & $5714(72.46 \%)$ & $6215(70.07 \%)$ & $6365(70.46 \%)$ & $13511(68.98 \%)$ \\
\hline Female & $2171(27.54 \%)$ & $2655(29.93 \%)$ & $2668(29.54 \%)$ & $6077(31.02 \%)$ \\
\hline \multicolumn{5}{|l|}{ Age of household head } \\
\hline Mean (SD) in years & $41.54(16.10)$ & $42.13(15.81)$ & $42.1(15.63)$ & $42.23(16.04)$ \\
\hline 95\% Confidence Interval & $40.99-42.08$ & $41.59-42.68$ & $41.53-42.66$ & $41.83-42.64$ \\
\hline \multicolumn{5}{|l|}{ Wealth index of household } \\
\hline Lowest & $1617(20.50 \%)$ & $1798(20.27 \%)$ & $1719(19.03 \%)$ & $3838(19.59 \%)$ \\
\hline Second Lowest & $1203(15.26 \%)$ & $1788(20.15 \%)$ & $1767(19.56 \%)$ & $3753(19.16 \%)$ \\
\hline Middle & $1207(15.31 \%)$ & $1709(19.27 \%)$ & $1672(18.51 \%)$ & $3616(18.46 \%)$ \\
\hline Fourth & $1436(18.21 \%)$ & $1650(18.60 \%)$ & $1723(19.08 \%)$ & $3916(19.98 \%)$ \\
\hline Highest & $2422(30.72 \%)$ & $1925(21.70 \%)$ & $2152(23.82 \%)$ & $4467(22.81 \%)$ \\
\hline \multicolumn{5}{|c|}{ Education attainment of household head } \\
\hline No education & $1853(23.60 \%)$ & $1783(20.19 \%)$ & $1586(17.59 \%)$ & $2932(14.97 \%)$ \\
\hline Incomplete primary & $3332(42.44 \%)$ & $3880(43.93 \%)$ & $3607(40.00 \%)$ & $7288(37.21 \%)$ \\
\hline Complete primary & $892(11.36 \%)$ & $1120(12.68 \%)$ & $1138(12.62 \%)$ & $2759(14.08 \%)$ \\
\hline Incomplete secondary & $1109(14.12 \%)$ & $1298(14.70 \%)$ & $1668(18.50 \%)$ & $3661(18.69 \%)$ \\
\hline Complete secondary & $82(1.04 \%)$ & $113(1.28 \%)$ & $205(2.27 \%)$ & $463(2.36 \%)$ \\
\hline Higher & $492(6.27 \%)$ & $588(6.66 \%)$ & $759(8.41 \%)$ & $2182(11.41 \%)$ \\
\hline
\end{tabular}




\begin{tabular}{|lllll|}
\hline Household characteristics & $2000 / 2001$ & 2006 & 2011 & 2016 \\
\hline Do not know & $92(1.17 \%)$ & $50(0.57 \%)$ & $55(0.61 \%)$ & $303(1.55 \%)$ \\
\hline
\end{tabular}

In all the surveys, the majority of households used wood as a cooking fuel, ranging from as high as $82.08 \%$ in 2006 to as low as $71.69 \%$ in 2016 . The majority of the households cooked their food in a separate building (ranging from as high as $63.62 \%$ in 2016 to as low as $59.83 \%$ in 2006). For those who cooked their food in the house, the majority did not have a separate room used as a kitchen, ranging from as high as $67.00 \%$ in 2006 to as low as $66.13 \%$ in 2016 . The majority of the households were exposed to HAP with a proportion of $96.69 \%, 99.80 \%, 99.03 \%$, and $99.00 \%$ in 2000/2001, 2006, 2011, and 2016 respectively (Table 2). Figure 1 illustrates the changes in the proportion of households exposed to household air pollution in Uganda from 2000/2001 to 2016. Figure 2 illustrates the proportions of HAP in the regions of Uganda from 2001/2001 to 2016. 
Table 2

Cooking fuel use and Household Air Pollution (HAP) in the households in Uganda (2000/01 to 2016).

$\begin{array}{llll}2000 / 2001 & 2006 & 2011 & 2016\end{array}$

\section{Type of cooking fuel}

Wood

Charcoal

Kerosene

Electricity

Lpg/cylinder

Biogas

Straw/shrubs/grass

Agricultural crop

Dung
$6363(81.29 \%)$

$1200(15.34 \%)$

$192(2.46 \%)$

$61(0.78 \%)$

$2(0.02 \%)$

$4(0.05 \%)$

$0(0.00 \%)$

$0(0.00 \%)$

$5(0.06 \%)$
$7074(82.08 \%)$

$1396(16.20 \%)$

$104(1.21 \%)$

$4(0.05 \%)$

$9(0.10 \%)$

$4(0.05 \%)$

$26(0.31 \%)$

$0(0.00 \%)$

$0(0.00 \%)$
$6550(74.35 \%) \quad 13590(71.69 \%)$

$2060(23.38 \%) \quad 4980(26.27 \%)$

$97(1.10 \%)$

$28(0.32 \%)$

$40(0.46 \%)$

$17(0.19 \%)$

$18(0.21 \%)$

$0(0.00 \%)$

$0(0.00 \%)$
$140(0.74 \%)$

$76(0.40 \%)$

$96(0.51 \%)$

$18(0.09 \%)$

$50(0.26 \%)$

$6(0.03 \%)$

$0(0.00 \%)$

\section{Where food is cooked a}

\begin{tabular}{lllll}
\hline In the house & - & $1224(14.22 \%)$ & $1020(11.59 \%)$ & $2158(11.39 \%)$ \\
\hline In a separate building & - & $5149(59.83 \%)$ & $5268(59.85 \%)$ & $12049(63.62 \%)$ \\
\hline Outdoors & - & $2233(2595 \%)$ & $2513(28.56 \%)$ & $4732(24.99 \%)$
\end{tabular}

The Household has a separate room used as a kitchen a

$\begin{array}{lllll}\text { No } & - & 807(67.00 \%) & 678(66.44 \%) & 1427(66.13 \%) \\ \text { Yes } & - & 398(33.00 \%) & 342(33.56 \%) & 731(33.87 \%)\end{array}$

\section{Cook in house ${ }^{\text {a }}$}

\begin{tabular}{|lllll|} 
Wood & - & $924(75.54 \%)$ & $419(41.09 \%)$ & $645(29.90 \%)$ \\
\hline Charcoal & - & $206(16.82 \%)$ & $468(45.89 \%)$ & $1279(59.25 \%)$ \\
\hline Kerosene & - & $78(6.37 \%)$ & $64(6.31 \%)$ & $88(4.09 \%)$ \\
\hline Electricity & - & $4(0.32 \%)$ & $23(2.28 \%)$ & $50(2.33 \%)$ \\
\hline Lpg/cylinder & - & $7(0.56 \%)$ & $32(3.12 \%)$ & $72(3.36 \%)$
\end{tabular}

\section{Footnote}

a For the 2000/2001 Uaanda DHS survev, there were no variables on where the food in the household Loading [MathJax]/jax/output/CommonHTML/fonts/TeX/fontdata.js 


\begin{tabular}{|c|c|c|c|c|}
\hline & $2000 / 2001$ & 2006 & 2011 & 2016 \\
\hline Biogas & - & $4(0.32 \%)$ & $12(1.14 \%)$ & $16(0.73 \%)$ \\
\hline Straw/shrubs/grass & - & $1(0.06 \%)$ & $2(0.17 \%)$ & $7(0.34 \%)$ \\
\hline Agricultural crop & - & $0(0.00 \%)$ & $0(0.00 \%)$ & $0(0.00 \%)$ \\
\hline \multicolumn{5}{|c|}{ Cook in a separate building a } \\
\hline Wood & - & 4804 (93.29\%) & 4695 (89.20\%) & 10534 (87.35\%) \\
\hline Charcoal & - & 317 (6.17\%) & $542(10.30 \%)$ & 1440 (11.95\%) \\
\hline Kerosene & - & $5(0.11 \%)$ & $7(0.14 \%)$ & $15(0.12 \%)$ \\
\hline Electricity & - & $0(0.00 \%)$ & $5(0.09 \%)$ & $13(0.11 \%)$ \\
\hline Lpg/cylinder & - & $2(0.04 \%)$ & $5(0.09 \%)$ & $21(0.18 \%)$ \\
\hline Biogas & - & $1(0.01 \%)$ & $4(0.07 \%)$ & $2(0.02 \%)$ \\
\hline Straw/shrubs/grass & - & $19(0.38 \%)$ & $6(0.11 \%)$ & $26(0.22 \%)$ \\
\hline Agricultural crop & - & $0(0.00 \%)$ & $0(0.00 \%)$ & $6(0.05 \%)$ \\
\hline \multicolumn{5}{|l|}{ Cook outdoors ${ }^{a}$} \\
\hline Wood & - & $1334(59.75 \%)$ & $1425(56.71 \%)$ & $2405(50.58 \%)$ \\
\hline Charcoal & - & $872(39.04 \%)$ & $1047(41.65 \%)$ & $2257(47.71 \%)$ \\
\hline Kerosene & - & 21 (0.93\%) & 25 (1.00\%) & 37 (0.78\%) \\
\hline Electricity & - & $0(0.00 \%)$ & $0(0.00 \%)$ & $12(0.25 \%)$ \\
\hline Lpg/cylinder & - & $0(0.00 \%)$ & $3(0.14 \%)$ & $3(006 \%)$ \\
\hline Biogas & - & $0(0.00 \%)$ & $2(0.07 \%)$ & $0((0.00 \%)$ \\
\hline Straw/shrubs/grass & - & $6(0.28 \%)$ & $11(0.43 \%)$ & $16(0.35 \%)$ \\
\hline Agricultural crop & - & $0(0.00 \%)$ & $0(0.00 \%)$ & $0(0.00 \%)$ \\
\hline \multicolumn{5}{|c|}{ Household Air Pollution } \\
\hline No & $259(3.31 \%)$ & $17(0.20 \%)$ & $85(0.97 \%)$ & $190(1.00 \%)$ \\
\hline Yes & 7568 (96.69\%) & 8601 (99.80\%) & 8724 (99.03\%) & 18766 (99.00\%) \\
\hline \multicolumn{5}{|l|}{ Footnote } \\
\hline $\begin{array}{l}\text { a For the } 2000 / 2001 \\
\text { was cooked. }\end{array}$ & a DHS surve & e were no vari & on where the & in the household \\
\hline
\end{tabular}




\section{Household characteristics associated with HAP.}

From the multivariate logistic regression analysis, households located in a rural area were more likely to be exposed to HAP [Adjusted Odd ratio: 1.87, 95\% Confidence interval (1.24-2.83), p-value $=0.003$ ] when compared with households located in urban areas. Also, households in the second-lowest [Adjusted Odd ratio: 44.7, 95\% Confidence interval (5.98-334.21p value < 0.001 ], middle [Adjusted Odd ratio: 7.00, 95\% Confidence interval (2.86-17.14)p-value $<0.001$ ] and fourth [Adjusted Odd ratio: 9.2, 95\% Confidence interval (4.15-20.39), p-value < 0.001] wealth index were more likely to be exposed to HAP when compared with households in the lowest wealth index. Households with a household head having attained either complete secondary education [Adjusted Odd ratio: $0.13,95 \%$ Confidence interval (0.030.58), $p$-value $=0.008$ ] or higher education [Adjusted Odd ratio: $0.11,95 \%$ Confidence interval (0.03-0.48), $\mathrm{p}$-value $=0.003$ ] were less likely to be exposed to HAP when compared with households with a household head having no education (Table 3 ). 
Table 3

Household Factors associated with Household Air Pollution (HAP) in Uganda (Using Uganda DHS conducted 2016)

\begin{tabular}{|c|c|c|c|c|}
\hline & Crude Odd ration (95\% Cl) & $\begin{array}{l}\mathrm{P}- \\
\text { value }\end{array}$ & Adjusted Odd ratio & $\begin{array}{l}\mathrm{P}- \\
\text { value }\end{array}$ \\
\hline $\begin{array}{l}\text { Number of household } \\
\text { members }\end{array}$ & $1.42(1.31-1.53)$ & $<.001$ & $1.29(1.19-1.41)$ & $\begin{array}{l}<.001 \\
0.01\end{array}$ \\
\hline Age of household head & $1.02(1.01-1.03)$ & $\begin{array}{l}<.001 \\
0.00\end{array}$ & $0.99(0.98-1.00)$ & 0.201 \\
\hline \multicolumn{5}{|l|}{ Type of place } \\
\hline Urban & 1 & & 1 & \\
\hline Rural & $13.79(9.54-19.93)$ & $<.001$ & $1.87(1.24-2.83)$ & 0.003 \\
\hline \multicolumn{5}{|c|}{ Sex of the household head } \\
\hline Male & 1 & & - & - \\
\hline Female & $1.14(0.82-1.58)$ & 0.44 & - & - \\
\hline \multicolumn{5}{|c|}{ Level of education of household head } \\
\hline No education & 1 & & 1 & \\
\hline Incomplete primary & $0.29(0.07-1.26)$ & 0.098 & $0.46(0.10-2.02)$ & 0.301 \\
\hline Complete primary & $0.56(0.09-3.34)$ & 0.522 & $1.41(0.23-8.66)$ & 0.709 \\
\hline Incomplete secondary & $0.09(0.02-0.37)$ & 0.001 & $0.48(0.11-2.14)$ & 0.338 \\
\hline Complete secondary & $0.01(0.003-0.05)$ & $\begin{array}{l}<.001 \\
0.00\end{array}$ & $0.13(0.03-0.58)$ & 0.008 \\
\hline Higher & $0.01(0.003-0.045)$ & $<.001$ & $0.11(0.03-0.48)$ & 0.003 \\
\hline Do not know & $0.03(0.006-0.159)$ & $\begin{array}{l}<.001 \\
0 .\end{array}$ & $0.18(0.03-0.95)$ & 0.044 \\
\hline \multicolumn{5}{|l|}{ Wealth index } \\
\hline Lowest & $1^{\mathrm{a}}$ & & $1^{\mathrm{a}}$ & \\
\hline Second Lowest & $175.00(24.49-1250.6)$ & $<.001$ & $44.7(5.98-334.21)$ & $\hat{0.001}$ \\
\hline
\end{tabular}

\section{Footnote}

a Predicts success perfectly (dropped and 4458 observations not used). ${ }^{b}$ Omitted because of Loading [MathJax]/jax/output/CommonHTML/fonts/TeX/fontdata.js 


\begin{tabular}{|c|c|c|c|c|}
\hline & Crude Odd ration (95\% Cl) & $\begin{array}{l}\mathrm{P}- \\
\text { value }\end{array}$ & Adjusted Odd ratio & $\begin{array}{l}\mathrm{P}- \\
\text { value }\end{array}$ \\
\hline Middle & $26.33(11.64-59.55)$ & $<.001$ & $7.00(2.86-17.14)$ & <. 001 \\
\hline Fourth & $22.47(10.53-47.95)$ & $<.001$ & $9.2(4.15-20.39)$ & <. 001 \\
\hline Highest & $\begin{array}{l}1^{\mathrm{b}} \text { (omitted because of } \\
\text { collinearity) }\end{array}$ & - & $\begin{array}{l}1^{b} \text { (omitted because of } \\
\text { collinearity) }\end{array}$ & \\
\hline \multicolumn{5}{|c|}{ Footnote } \\
\hline $\begin{array}{l}\text { a Predict } \\
\text { collinear }\end{array}$ & dropped and 4458 obse & 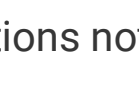 & used). ${ }^{b}$ Omitted because of & \\
\hline
\end{tabular}

\section{Discussion}

In this study, we describe the trends of exposure of Ugandan households to household air pollution (HAP) contributed by the type of cooking fuel they used over a 16-year period (from 2000 to 2016). We analyzed data from the demographic and health surveys (DHS) conducted in Uganda from 2000/2001 to 2016. Our findings revealed that the majority of the households used wood as cooking fuel, cooked their food in a separate building and those who cooked their food in the house did not have a separate room used as a kitchen. Overall, most of the households were exposed to HAP with an increasing trend from 2000/2001 to 2016. From this study, household characteristics like the number of household members, type of place of residence (rural vs urban), level of education of household head, and wealth index were associated with exposure to HAP.

From this study, the most used cooking fuel in Ugandan households was wood with the proportion of households using it ranging from $71.69-83.08 \%$. It is consistent with studies from other low- and middleincome countries (LMICs) like in Malawi, and Zimbabwe where wood is the most common cooking fuel due to its affordability and easy accessibility [10-14]. Using wood as a cooking fuel has been shown to contribute greatly to pollution in households [15]. Innovations to reduce exposure to pollution caused by wood for example the use of briquettes and improved wood-burning stoves have been developed for use in LMICs $[16,17]$. Also, our study found that slightly more than half of households who cooked outdoors used wood while $87.35-93.29 \%$ of those who cooked in a separate building used wood. Previous studies have shown that cooking using wood in a building has been found to have greater exposure to household pollution when compared with outdoor cooking [18].

From our study, the proportion of households exposed to HAP caused by the type of cooking fuel used was high, ranging from $96.69-99.80 \%$. This is consistent with findings from studies from other LMICs where the proportion of households exposed to HAP caused by the type of cooking fuel was high $[12,19]$. 
From this study, households located in a rural area were more likely to be exposed to HAP as compared to those located in urban areas. It is consistent with studies from countries in Africa and Asia where households in rural areas were more likely to use cooking fuels that expose them to $\operatorname{HAP}[12,19,20]$. This could be because the cooking fuels that cause greater exposure to HAP are cheap and easily accessible in low-income settings like rural areas $[10,11,13]$. Also, this study found that households in the second, middle and fourth wealth index were less likely to be exposed to HAP when compared with those in the lowest wealth index. This could also be explained by the affordability of cleaner cooking fuels by households with an increasing wealth index which has shown to be a determinant of household fuel use $[21,22]$.

Another finding from this study was that households with a household head having attained either complete secondary education or higher education were less likely to be exposed to HAP when compared to those with no education. This accords with findings from studies in other countries like China, and Malawi $[23,24]$. Household heads who have completed secondary or higher education like university education have been found to have better knowledge of the source of $\operatorname{HAP}[25,26]$. A possible explanation for this might be that they have better decision-making in using a cleaner source of energy for cooking in their households.

\section{Conclusion}

Most households in Uganda have exposure to household air pollution caused by the type of cooking fuel used. This justifies the need for innovations that can reduce the exposure to household air pollution caused by cooking fuels.

\section{Declarations}

\section{Ethics approval and consent to participate}

Ethical approval for the Demographic and Health Surveys is obtained from relevant research ethical approval committees and research regulatory bodies before data collection. We obtained permission to use the DHS survey datasets from the DHS program website. No personally identifiable information is available in the used datasets.

\section{Consent for publication}

Not Applicable

\section{Availability of data and materials}


The datasets generated and/or analyzed during the current study are available in the Demographic and Health Survey program website, https://dhsprogram.com/data/available-datasets.cfm and can be accessed after obtaining approval.

\section{Competing interests}

The authors declare that they do not have any competing interests.

\section{Funding}

The authors did not receive any funding for this work.

\section{Authors contributions}

DBA, NR, SBW, and AS conceived the study. DBA and AS requested data from the DHS program website, performed statistical analysis, interpretation of data and spearheaded the writing of the manuscript.AP, EKN, AM, RKK, YAA, and DELP discussed the relevant results. DBA, NR, SBW, AS, PA, EKN, AM, RKK, YAA, and DELP contributed to the writing of the manuscript, read, and approved the final manuscript.

\section{Acknowledgements}

We thank the Demographic and Health Survey (DHS) program for granting us access to the DHS datasets used in this study

\section{References}

1. Murray CJL, Barber RM, Foreman KJ, Ozgoren AA, Abd-Allah F, Abera SF, et al. Global, regional, and national disability-adjusted life years (DALYs) for 306 diseases and injuries and healthy life expectancy (HALE) for 188 countries, 1990-2013: quantifying the epidemiological transition. Lancet. 2015;386:2145-91.

2. Roth GA, Abate D, Abate KH, Abay SM, Abbafati C, Abbasi N, et al. Global, regional, and national agesex-specific mortality for 282 causes of death in 195 countries and territories, 1980-2017: a systematic analysis for the Global Burden of Disease Study 2017. Lancet. 2018;392:1736-88.

3. Apte K, Salvi S. Household air pollution and its effects on health. F1000Research. 2016;5.

4. Liu J, Hou B, Ma X-W, Liao H. Solid fuel use for cooking and its health effects on the elderly in rural China. Environ Sci Pollut Res. 2018;25:3669-80.

5. Murray CJL, Aravkin AY, Zheng P, Abbafati C, Abbas KM, Abbasi-Kangevari M, et al. Global burden of 87 risk factors in 204 countries and territories, 1990-2019: a systematic analysis for the Global Rurden of Diceace Studv 2019 I anret 2n2n·296.12?3-49. 
6. Rutstein SO, Rojas G. Guide to DHS statistics. Calverton, MD ORC Macro. 2006;38:12-4.

7. Corsi DJ, Neuman M, Finlay JE, Subramanian S V. Demographic and health surveys: a profile. Int J Epidemiol. 2012;41:1602-13.

8. StataCorp. STATA SURVEY DATA REFERENCE MANUAL RELEASE 13. Texas, USA: Stata Press; 2013. https://public.econ.duke.edu/stata/Stata-13-Documentation/svy.pdf.

9. Croft TN, Marshall AMJ, Allen CK, Arnold F, Assaf S, Balian S. Guide to DHS statistics. Rockville, Maryland, USA; 2018. https://www.dhsprogram.com/pubs/pdf/DHSG1/Guide_to_DHS_Statistics_DHS-7_v2.pdf.

10. Heltberg R. Factors determining household fuel choice in Guatemala. Environ Dev Econ. 2005;10:337-61. doi:DOI: 10.1017/S1355770X04001858.

11. Hernández-Garduño E, Gómez-García E, Campos-Gómez S. Prevalence trends of wood use as the main cooking fuel in Mexico, 1990-2013. Salud Publica Mex. 2017;59:68-75.

12. Makonese T, Ifegbesan AP, Rampedi IT. Household cooking fuel use patterns and determinants across southern Africa: Evidence from the demographic and health survey data. Energy Environ. 2018;29:29-48.

13. Paudel U, Khatri U, Pant KP. Understanding the determinants of household cooking fuel choice in Afghanistan: a multinomial logit estimation. Energy. 2018;156:55-62.

14. Zulu LC, Richardson RB. Charcoal, livelihoods, and poverty reduction: Evidence from sub-Saharan Africa. Energy Sustain Dev. 2013;17:127-37.

15. Elf JL, Kinikar A, Khadse S, Mave V, Suryavanshi N, Gupte N, et al. Sources of household air pollution and their association with fine particulate matter in low-income urban homes in India. J Expo Sci Environ Epidemiol. 2018;28:400-10. doi:10.1038/s41370-018-0024-2.

16. Njenga M, Gitau JK, liyama M, Jamnadassa R, Mahmoud Y, Karanja N. Innovative biomass cooking approaches for sub-Saharan Africa. African J Food, Agric Nutr Dev. 2019;19:14066-87.

17. Zuk M, Rojas L, Blanco S, Serrano P, Cruz J, Angeles F, et al. The impact of improved wood-burning stoves on fine particulate matter concentrations in rural Mexican homes. J Expo Sci Environ Epidemiol. 2007;17:224-32. doi:10.1038/sj.jes.7500499.

18. Saksena S, Singh PB, Prasad RK, Prasad R, Malhotra P, Joshi V, et al. Exposure of infants to outdoor and indoor air pollution in low-income urban areas - a case study of Delhi. J Expo Sci Environ Epidemiol. 2003;13:219-30. doi:10.1038/sj.jea.7500273.

19. Bickton FM, Ndeketa L, Sibande GT, Nkeramahame J, Payesa C, Milanzi EB. Household air pollution and under-five mortality in sub-Saharan Africa: an analysis of 14 demographic and health surveys. Environ Health Prev Med. 2020;25:67. doi:10.1186/s12199-020-00902-4.

20. Arku RE, Ezzati M, Baumgartner J, Fink G, Zhou B, Hystad P, et al. Elevated blood pressure and household solid fuel use in premenopausal women: Analysis of 12 Demographic and Health Surveys (DHS) from 10 countries. Environ Res. 2018;160:499-505.

doi:https://doi.org/10.1016/j.envres.2017.10.026.

Loading [MathJax]/jax/output/CommonHTML/fonts/TeX/fontdata.js

Page 16/19 
21. Makonese T, Ifegbesan AP, Rampedi IT. Household cooking fuel use patterns and determinants across southern Africa: Evidence from the demographic and health survey data. Energy Environ. 2017;29:29-48. doi:10.1177/0958305X17739475.

22. Yadama GN, Peipert J, Sahu M, Biswas P, Dyda V. Social, Economic, and Resource Predictors of Variability in Household Air Pollution from Cookstove Emissions. PLoS One. 2012;7:e46381. https://doi.org/10.1371/journal.pone.0046381.

23. PAPINEAU M, AUNAN K, BERNTSEN T. Distributional determinants of household air pollution in China. Environ Dev Econ. 2009;14:621-39. doi:DOI: 10.1017/S1355770X0900521X.

24. Piddock KC, Gordon SB, Ngwira A, Msukwa M, Nadeau G, Davis KJ, et al. A cross-sectional study of household biomass fuel use among a periurban population in Malawi. Ann Am Thorac Soc. 2014;11:908-14.

25. Ferguson L, Taylor J, Davies M, Shrubsole C, Symonds P, Dimitroulopoulou S. Exposure to indoor air pollution across socio-economic groups in high-income countries: A scoping review of the literature and a modelling methodology. Environ Int. 2020;143:105748. doi:https://doi.org/10.1016/j.envint.2020.105748.

26. Raufman J, Blansky D, Lounsbury DW, Mwangi EW, Lan Q, Olloquequi J, et al. Environmental health literacy and household air pollution-associated symptoms in Kenya: a cross-sectional study. Environ Heal. 2020;19:89. doi:10.1186/s12940-020-00643-5.

\section{Figures}




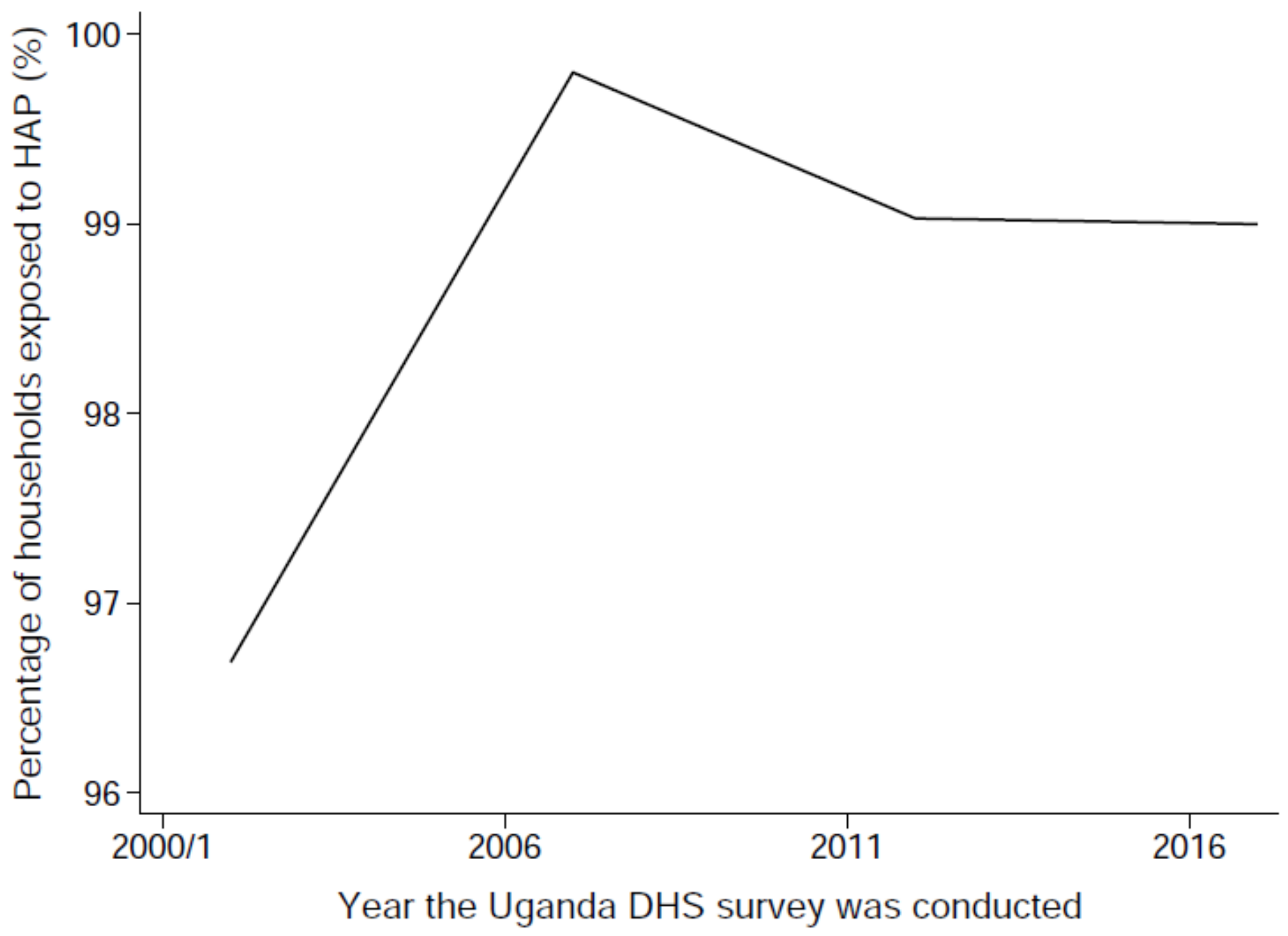

Figure 1

Percentage of households exposed to HAP in Uganda for the period 2000/2001 to 2016. 

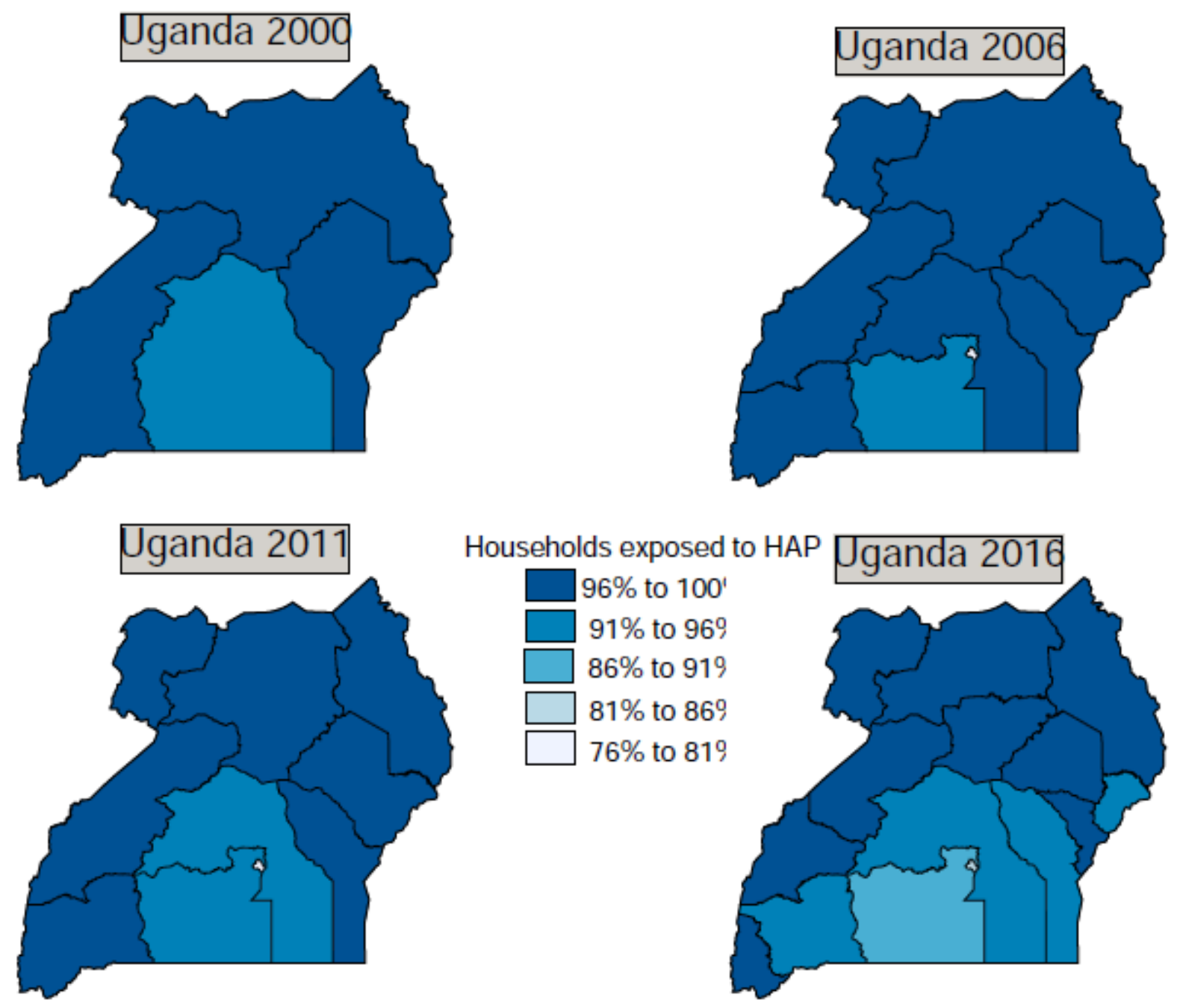

\section{Figure 2}

Proportion of households exposed to household air pollution in Uganda by region from 2000/2001 to 2016. 